\title{
Resposta de plantas ao condicionamento osmótico de sementes de girassol
}

\section{Plant response to sunflower seeds to osmotic conditioning}

\author{
Camila Santos Barros de Morais $^{1 *}$; Lilian Guimarães de Almeida ${ }^{2}$; \\ Marcus Barros dos Santos ${ }^{2}$; Claudia Antonia Vieira Rossetto ${ }^{3}$
}

\begin{abstract}
Resumo
O objetivo deste trabalho foi avaliar o efeito do condicionamento osmótico de sementes na emergência de plântulas e no desempenho de plantas de girassol. Sementes de três lotes de girassol da cultivar Catissol foram submetidas ao condicionamento osmótico com solução de polietilenoglicol a $-2,0$ MPa em sistema aerado, sob $15^{\circ} \mathrm{C}$ por 8 horas e, posteriormente avaliadas pelos testes de germinação e de vigor. Em condições de campo, realizaram-se as avaliações de emergência de plântulas, de desenvolvimento das plantas, de produtividade e qualidade das sementes produzidas, bem como o acúmulo de macronutrientes nas sementes produzidas. O condicionamento osmótico favorece a sobrevivência das plantas, o acúmulo de massa de matéria seca da parte aérea de plantas a partir de 60 dias após a semeadura e o teor de óleo, em plantas provenientes de lotes de sementes de qualidade inferior. O condicionamento osmótico não aumenta a produtividade de sementes, mas favorece o vigor das sementes produzidas, independente da qualidade de sementes do lote utilizado na semeadura.

Palavras-chave: Helianthus annuиs L., crescimento, produtividade, qualidade fisiológica
\end{abstract}

\begin{abstract}
The aim of this study was to evaluate the effect of seeds osmotic conditioning in seedlings emergence and plants performance of sunflower. Three lots of seeds sunflower (Catissol), was submited to osmotic conditioning with polyethylene glycol solution, $-2,0 \mathrm{MPa}$ in aerated system, under $15{ }^{\circ} \mathrm{C}$ for 8 hour and then was evaluated for germination tests and vigour. Under filed conditions was conducted emergency evaluations of seedling, plants development as well as the productivity and seeds quality, and the accumulation of nutrients in the seeds. The osmotic conditioning improve the survival of seedling, the dry matter mass to aerial part of plants from 60 days after sowing and oil content, in lots with low seeds physiological quality. The osmotic conditioning not increase the seeds yield but promotes the vigour of seeds produced, regardless of the lot used for sowing seeds.
\end{abstract}

Key words: Helianthus annuus L., growth, productivity, quality

${ }^{1}$ Eng $^{\text {a }}$ Agr $^{\text {a }}$, Discente do Curso de Doutorado em Fitotecnia, Dept ${ }^{\circ}$ de Fitotecnia da Universidade Federal Rural do Rio de Janeiro, UFRRJ, Seropédica, RJ. E-mail: sbcamila@yahoo.com.br

${ }^{2}$ Discentes do Curso de Agronomia, UFRRJ, Seropédica, RJ. E-mail:liliangalmeida@yahoo.com.br; marcusagronomo@yahoo. com.br

${ }^{3}$ Eng $^{\mathrm{a}}$ Agr $^{\mathrm{a}}$, Prof ${ }^{\mathrm{a}}$ Associada IV, Dept ${ }^{\mathrm{o}}$ de Fitotecnia, UFRRJ, Seropédica, RJ. E-mail: cavrosse@ufrrj.br

* Autor para correspondência 


\section{Introdução}

O girassol vem ganhando destaque entre as culturas, por se adaptar a diferentes áreas de cultivo e apresentar $45 \%$ de óleo em suas sementes, além de ser uma excelente opção de segunda safra aos produtores, sendo utilizada como rotação, sucessão. De acordo com a CONAB (2013) houve aumento na produção entre os anos de 2012 e 2013. No entanto para adequada produção desta espécie, tem-se como obstáculo a falta de sincronismo da germinação, que proporciona desuniformidade no estabelecimento das plantas em campo (MWALE; HAMUSIMBI; MWANSA, 2003).

$\mathrm{Na}$ tentativa de diminuir o período entre a semeadura e a emergência de plântulas, existem diferentes tratamentos pré semeadura, os quais vêm sendo estudados para diversas espécies, entre eles, o condicionamento osmótico. Este consiste na hidratação das sementes em soluções de baixo potencial osmótico por determinado período, visando desencadear os eventos metabólicos iniciais da germinação sem a ocorrência da emissão da raiz primária (HEYDECKER; HIGGINS; TURNER, 1975).

Para Marcos Filho (2005) o controle da embebição via osmocondicionamento possibilita que as sementes menos vigorosas tenham tempo suficiente para reparação e, ou, reorganização das membranas, visando alcançar o estádio de atividade metabólica semelhante às mais vigorosas. Além disso, esta técnica tem-se mostrado eficiente principalmente sob condições de estresse, tais como, alta temperatura do ar e restrição hídrica do substrato durante a germinação (SANCHEZ; ORTA; MUNOZ, 2001). Os resultados favoráveis podem estar relacionados ao estimulo e a síntese de enzimas antioxidantes (KIMBINZA et al., 2011), assim como a ativação de componentes energéticos para a síntese de novos RNA e proteínas, disponibilizando as sementes substâncias precursoras para produção das macromoléculas (WAHID et al., 2008).

Em girassol, o condicionamento com solução de polietilenoglicol (PEG) 6000 a $-2 \mathrm{MPa}$ e de $\mathrm{KNO}_{3} \mathrm{a}-0,3 \mathrm{MPa}$ proporcionou valores elevados de germinação e vigor das sementes, quando este foi avaliado pelo teste de envelhecimento acelerado (BARROS; ROSSETTO, 2009). Em condições de campo, Mwale, Hamusimbi e Mwansa (2003) verificaram que o condicionamento com PEG 8000 a $-0,6 \mathrm{MPa}$, promoveu maior sincronismo de germinação e emergência de plântulas desta espécie.

Em outras oleaginosas, também foi constatado o favorecimento do crescimento das culturas pelo emprego do condicionamento osmótico. Plantas de canola provenientes de sementes submetidas ao condicionamento com PEG 10.000 por 8 horas apresentaram maior índice de área foliar e maior acúmulo de massa de matéria seca (BASRA et al., 2003). Já quanto ao efeito desta técnica na produção os autores constataram aumento da produção de sementes de canola $\left(\mathrm{kg} \mathrm{ha}^{-1}\right)$, quando as sementes utilizadas tinham sido condicionadas. Além disso, em plantas de soja provenientes de sementes condicionadas com PEG 8.000 sob-1,1 MPa por 6 horas, Arif et al. (2008) verificaram elevada produção de sementes por hectare.

O objetivo foi avaliar o efeito do condicionamento osmótico de sementes na emergência de plântulas e no desempenho das plantas de girassol. Estudos referentes aos efeitos do condicionamento fisiológico sobre o comportamento de plantas à campo ainda não foram totalmente elucidados, sendo que a maioria dos trabalhos somente vão até a fase de plântulas. Além disto, a observação do comportamento pós fase de plântula é de grande importância, pelo fato do condicionamento fisiológico favorecer o sincronismo de germinação, diminuindo o tempo de exposição a estresses ambientais, proporcionando maior chance de crescimento das plantas e uma maturação mais uniforme das sementes produzidas.

\section{Material e Métodos}

O trabalho foi realizado nos anos de 2009 (em laboratório) e 2010 (em campo), com três lotes 
de sementes com pericarpo (aquênios) de girassol (Helianthus annuus L.) da cultivar Catissol 01, provenientes da Coordenadoria de Assistência Técnica Integral. Após o recebimento das sementes, estas ficaram armazenadas em câmara a $19^{\circ} \mathrm{C}$ e $46 \%$ umidade relativa do ar por três meses até a avaliação inicial da qualidade fisiológica. Os delineamentos utilizados foram o inteiramente casualizado em esquema fatorial (3 lotes x 2 tratamentos), com quatro repetições, para condições de laboratório e o de blocos ao acaso em parcelas subsubdivididas, com quatro repetições, para condições de campo (massa de matéria seca e índice de área foliar), por época de avaliação. Neste, a parcela foi representada pelos três lotes de sementes; a subparcela, pelos tratamentos (sementes submetidas ou não ao condicionamento osmótico) e, a subsubparcela por sete épocas de avaliação (15, 30, 45, 60, 75, 90 e 97 dias após a semeadura-DAS).

\section{Tratamento de sementes}

Em condição de laboratório, as sementes de cada lote foram ou não submetidas ao condicionamento osmótico com solução de polietilenoglicol (PEG 6000) a $-2,0 \mathrm{MPa}$ em sistema aerado, sob 15 ${ }^{\circ} \mathrm{C}$ por 8 horas (BARROS; ROSSETTO, 2009). Posteriormente, estas sementes foram submetidas aos testes de germinação e de vigor (primeira contagem, envelhecimento acelerado e condutividade elétrica). $O$ teste de germinação foi conduzido com quatro subamostras de 50 sementes (BRASIL, 2009). Em conjunto ao teste de germinação foi avaliado o teste de primeira contagem (NAKAGAWA, 1999). O teste de envelhecimento acelerado foi realizado com 250 sementes, pelo método da solução saturada de $\mathrm{NaCl}$ (BRAZ et al., 2008). O teste de condutividade elétrica foi conduzido com quatro subamostras de 50 sementes (sem o pericarpo) em $75 \mathrm{~mL}$ por 24 horas (BRAZ et al., 2008).

\section{Experimento em condições de campo}

A semeadura do girassol foi realizada por subparcela, a qual continha 3 linhas de $2 \mathrm{~m}$ espaçadas entre si a $0,7 \mathrm{~m}$. As sementes de cada lote e tratamento foram semeadas em solo classificado como Argissolo, cujo resultado da análise química apresentava: pH(água) 6,0; Ca 3,25 $\mathrm{cmol}_{\mathrm{c}} \cdot \mathrm{dm}^{-3} ; \mathrm{Mg}$ $1,35 \mathrm{cmol}_{\mathrm{c}} \cdot \mathrm{dm}^{-3} ; \mathrm{P} 3,38$ (ppm) $\mathrm{mg} \mathrm{L}^{-1} ; \mathrm{K} 2,38$ (ppm) $\mathrm{mg} \mathrm{L}^{-1} ; \mathrm{H}+\mathrm{Al} 1,74 \mathrm{cmol}_{\mathrm{c}} \mathrm{dm}^{-3}$ e de $\mathrm{V} \% 73$.

Foi empregada a densidade de 45.000 sementes ha $^{-1}$, com base em Braz e Rossetto (2009), ou seja, foram distribuídas 4 sementes por metro linear, após considerar o teste de germinação. Para a adubação na semeadura, com base no resultado da análise de solo e em Raij et al. (1997), foram aplicados 10 $\mathrm{kg} \mathrm{ha-1}$ de $\mathrm{N}$ na forma de sulfato de amônio, $70 \mathrm{~kg}$ $\mathrm{ha}^{-1}$ de $\mathrm{P}_{2} \mathrm{O}_{5}$ na forma de fosfato super simples e $60 \mathrm{~kg} \mathrm{ha}^{-1}$ de $\mathrm{K}_{2} \mathrm{O}$ na forma de cloreto de potássio. Já, na adubação de cobertura, aos 30 DAS, foram aplicados $40 \mathrm{~kg} \mathrm{ha}^{-1}$ de $\mathrm{N}$ na forma de sulfato de amônio (RAIJ et al., 1997), e aplicação de 0,23 kg ha ${ }^{-1}$ de boro na forma de bórax.

Durante a condução do experimento, os dados médios diários de temperatura e precipitação pluvial foram adquiridos junto à estação experimental da PESAGRO-RIO. As capinas manuais foram realizadas até $60 \mathrm{DAS}$.

Em cada época de avaliação, as plantas contínuas em um metro linear foram cortadas manualmente ao nível do solo e analisadas quanto à altura, diâmetro do caule, diâmetro do capítulo e número de folhas, sendo os dados expressos por planta. Em seguida, as folhas foram separadas e submetidas à determinação da área foliar através do integrador, modelo LI 3100c Área Meter, que fornece leitura direta $\mathrm{em} \mathrm{cm}^{2}$, sendo os dados transformados em $\mathrm{m}^{2}$. Também foi realizada a determinação da massa de matéria seca da parte área total das plantas, após secagem em estufa de circulação de ar a $65^{\circ} \mathrm{C}$ até atingir massa constante, e os dados expressos em $\mathrm{g} \mathrm{m}^{-2}$. A avaliação da população inicial e final foi realizada aos 20 e 97 DAS, através da contagem do número de plantas em um metro linear. 


\section{Produção de sementes}

Também aos 97 DAS, foi realizada a avaliação dos componentes de produção. As plantas contínuas em um metro linear foram cortadas manualmente ao nível do solo. As sementes foram contadas e pesadas para a avaliação do número de sementes bem formadas (com cor, tamanho e forma característica da espécie) por capítulo, da produção de sementes por planta e da massa de 1.000 sementes. Além disso, foi realizada a avaliação da produtividade de sementes por área, considerando 3 linhas de um metro, espaçadas entre si a $0,7 \mathrm{~cm}\left(2,1 \mathrm{~m}^{2}\right)$. Os dados foram mantidos a 7\% de água, com base em Silva et al. (2009) e expressos em $\mathrm{kg} \mathrm{ha}^{-1}$. Também foi realizado o cálculo do índice de colheita da cultura, através da razão entre massa seca das sementes e a massa seca da parte aérea total (KVET et al., 1971).

\section{Qualidade fisiológica das sementes produzidas}

Após o beneficiamento manual, as sementes foram acondicionadas em embalagem de sacos de papel e armazenadas a $20,5{ }^{\circ} \mathrm{C}$ de temperatura média e $51 \%$ de umidade relativa do ar por três meses. Posteriormente as sementes dos três lotes provenientes de plantas oriundas de sementes condicionadas e não condicionadas por ocasião da semeadura, foram submetidas ao teste de retenção em peneira de crivo circular com $5,56 \mathrm{~mm}$ de diâmetro e ao teste de grau de umidade pelo método da estufa a $105{ }^{\circ} \mathrm{C} \pm 3{ }^{\circ} \mathrm{C}$ por 24 horas (BRASIL, 2009). A avaliação da qualidade fisiológica foi realizada pelo teste de germinação e vigor, seguindo a mesma metodologia utilizada por ocasião da avaliação inicial. Também realizou-se o teste de emergência de plântulas em areia e em campo, utilizando quatro subamostras de 50 sementes e avaliação durante 21 DAS (NAKAGAWA, 1999), cujos resultados foram expressos em porcentagem e velocidade de emergência das plântulas.

\section{Análise de macronutrientes nas sementes}

Na análise do acúmulo de nutrientes nas sementes, as amostras por lote e tratamento, previamente secas, foram moídas em moinho do tipo Willey, e em seguida, submetidas à digestão sulfúrica. As determinações de nitrogênio foram realizadas pelo procedimento Kjeldhal, as de fósforo, potássio, bem como as de cálcio e magnésio, foram realizadas por fotocolorimetria, fotômetro de chama e absorção atômica, respectivamente. Além disto, as sementes foram submetidas à determinação de óleo pelo método de Sohxlet.

\section{Análise estatística}

$\mathrm{Na}$ análise estatística foram realizados os testes de normalidade e homogeneidade das variâncias dos erros e, os dados foram submetidos aos testes de Lilliefors e de Cochran \& Bartley, respectivamente. Com os pressupostos atendidos, posteriormente, foram realizadas as análises de variância. Quando o teste $\mathrm{F}$ foi significativo para as fontes de variação qualitativa, foram comparadas as médias dos tratamentos pelo teste de Tukey $(p=0,05)$. Já, para a fonte de variação quantitativa, foi efetuada a análise de regressão, considerando a significância, o maior coeficiente de determinação e a expectativa biológica para o melhor ajuste da equação. No caso das interações significativas, foram realizados os desdobramentos necessários.

\section{Resultados e Discussão}

\section{Tratamento de sementes}

Houve efeito significativo da interação entre lotes e tratamentos somente para o vigor das sementes (Tabela 1). Assim, a germinação das sementes de girassol dos lotes 1 e 3 foi superior a das do lote 2 , independente das sementes terem ou não sido submetidas ao condicionamento osmótico (Tabela 1). Além disto, na avaliação do vigor, ao comparar os lotes, quando as sementes foram 
condicionadas $(\mathrm{C} / \mathrm{C})$ ou não condicionadas $(\mathrm{S} / \mathrm{C})$, foi constatado pelos testes de primeira contagem e de condutividade elétrica, a classificação dos lotes 1 e 3 como de vigor superior ao do lote 2 . E, apenas pelo teste de envelhecimento acelerado, houve separação dos lotes em três distintos níveis, indicando o lote 3 como de vigor intermediário, quando as sementes não foram condicionadas e como de nível superior, quando as sementes foram condicionadas (Tabela 1). Estes resultados do lote 3 podem estar relacionados à tolerância do lote 3 ao estresse térmico imposto pelo teste de envelhecimento acelerado (LIMA; MARCOS FILHO, 2011), principalmente após a ativação de componentes energéticos para a síntese de novos RNA e proteínas visando a produção das macromoléculas (WAHID et al., 2008), promovido pelo condicionamento osmótico. Já, comparandose os tratamentos, foi verificado que para o lote 1 , o condicionamento osmótico favoreceu o vigor avaliado pelo teste de primeira contagem; para o lote 2, pelo teste de condutividade elétrica e, para o lote 3 , pelos testes de primeira contagem, envelhecimento acelerado e condutividade elétrica (Tabela 1). Desta forma, os resultados indicam que o efeito do condicionamento osmótico é dependente da qualidade fisiológica inicial das sementes. De acordo com Marcos Filho (2005), sementes de lotes altamente vigorosos não respondem à esta técnica pois não necessitam de reparo metabólico, assim como também lotes que apresentam elevada proporção de sementes em estádio avançado de deterioração demandam intenso reparo, não sendo observado o sucesso esperado. Comparando os resultados, em girassol, o condicionamento com solução de polietilenoglicol (PEG) 6000 a -2 MPa e com solução de $\mathrm{KNO}_{3} \mathrm{a}-0,3 \mathrm{MPa}$ proporcionou valores elevados de germinação e vigor das sementes, quando este foi avaliado pelo teste de envelhecimento acelerado (BARROS; ROSSETTO, 2009).

\section{Experimento em condições de campo}

Houve efeito individual significativo de lotes para população de plantas (Tabela 1) e efeito significativo da interação entre lotes e tratamentos para sobrevivência de plantas (Tabela 2), bem como efeito individual significativo de tratamentos para diâmetro do caule (Tabela 2). Além disto, houve efeito significativo da interação entre lotes e tratamentos, por época na avaliação da massa de matéria seca e índice de área foliar (Tabelas 3 e 4). Assim, foi verificado que houve menor população (inicial e final) das plantas provenientes das sementes do lote 2, independente do tratamento (Tabela 1). E, independente do lote utilizado na semeadura, também não houve efeito de tratamentos para população de plantas. O condicionamento osmótico proporciona benefícios ao desenvolvimento das plantas de girassol, por promover maior desvio das reservas cotiledonares para a fase de crescimento das plântulas, crucial ao rápido estabelecimento da planta a campo, para que possa iniciar a atividade fotossintética, favorecendo ao crescimento mais vigoroso (WAHID et al., 2008). E, este efeito é mais notado em condições climáticas desfavoráveis (COSTA; VILELLA, 2006). Durante o cultivo, foram observados $5,48 \mathrm{~mm}$ de precipitação pluvial e $28^{\circ} \mathrm{C}$ de temperatura média do ar, que de acordo com Leite, Brighenti e Castro (2005), são condições favoráveis para o estabelecimento das plantas desta espécie. Além disto, na Tabela 1, ao comparar os lotes dentro de cada tratamento, foi constatado para os lotes 1 e 2 que o condicionamento osmótico favoreceu a sobrevivência das plantas. E, comparando-se os tratamentos, foi verificado apenas quando as sementes foram condicionadas, menor sobrevivência das plantas provenientes do lote 3 (Tabela 1). Estes resultados podem estar relacionados com o fato do efeito favorável desta técnica ocorrer preferencialmente em condições desfavoráveis e com lotes de qualidade fisiológica intermediaria. Este lote após o condicionamento apresentou vigor superior em condições de estresse térmico (Tabela 1). 
Tabela 1. Dados médios de germinação (\%), de plântulas normais na primeira contagem de germinação (\%), de envelhecimento acelerado com solução saturada (\%) e de condutividade elétrica $(\mathrm{mS} / \mathrm{cm} / \mathrm{g})$, de população inicial (\%), de população final (\%) e de sobrevivência (\%), obtidos de três lotes (L1, L2 e L3) de sementes de girassol submetidas (C/C) ou não(S/C) ao condicionamento osmótico.

\begin{tabular}{|c|c|c|c|c|c|c|c|}
\hline \multicolumn{8}{|c|}{ Em laboratório } \\
\hline \multirow{2}{*}{ Tratamentos } & \multirow{2}{*}{ Germinação } & \multicolumn{2}{|c|}{ Primeira contagem } & \multicolumn{2}{|c|}{ Envelhecimento acelerado } & \multicolumn{2}{|c|}{ Condutividade elétrica } \\
\hline & & $\mathrm{S} / \mathrm{C}$ & $\mathrm{C} / \mathrm{C}$ & $\mathrm{S} / \mathrm{C}$ & $\mathrm{C} / \mathrm{C}$ & $\mathrm{S} / \mathrm{C}$ & $\mathrm{C} / \mathrm{C}$ \\
\hline L1 & $86 a^{*}$ & $61 \mathrm{Ba}$ & $70 \mathrm{Aa}$ & $56 \mathrm{Aa}$ & $60 \mathrm{Ab}$ & $20,55 \mathrm{Ab}$ & $19,51 \mathrm{Ab}$ \\
\hline L2 & $81 \mathrm{~b}$ & $46 \mathrm{Ab}$ & $48 \mathrm{Ab}$ & $36 \mathrm{Ac}$ & 39Ac & $39,90 \mathrm{Aa}$ & $36,50 \mathrm{Ba}$ \\
\hline L3 & $86 a$ & $59 \mathrm{Ba}$ & $75 \mathrm{Aa}$ & $49 \mathrm{Bb}$ & $74 \mathrm{Aa}$ & $23,31 \mathrm{Ab}$ & $18,70 \mathrm{Bb}$ \\
\hline $\mathrm{S} / \mathrm{C}$ & $82 \mathrm{~A}$ & - & - & - & - & - & - \\
\hline $\mathrm{C} / \mathrm{C}$ & $88 \mathrm{~A}$ & - & - & - & - & - & - \\
\hline C.V. & 2,82 & \multicolumn{2}{|c|}{7,25} & \multicolumn{2}{|c|}{6,36} & \multicolumn{2}{|c|}{5,82} \\
\hline \multicolumn{8}{|c|}{ Em campo } \\
\hline \multirow{2}{*}{ Tratamentos } & \multirow{2}{*}{\multicolumn{3}{|c|}{ População inicial }} & \multirow{2}{*}{\multicolumn{2}{|c|}{ População final }} & \multicolumn{2}{|c|}{ Sobrevivência } \\
\hline & & & & & & $\mathrm{S} / \mathrm{C}$ & $\mathrm{C} / \mathrm{C}$ \\
\hline L1 & \multicolumn{3}{|c|}{$3,75 a$} & \multicolumn{2}{|c|}{$3,09 a$} & $71 \mathrm{Ba}$ & $90 \mathrm{Aa}$ \\
\hline L2 & \multicolumn{3}{|c|}{$3,0 \mathrm{~b}$} & \multicolumn{2}{|c|}{$2,63 b$} & $83 \mathrm{Ba}$ & 100Aa \\
\hline L3 & \multicolumn{3}{|c|}{$3,75 \mathrm{a}$} & \multicolumn{2}{|c|}{$2,88 \mathrm{a}$} & $80 \mathrm{Aa}$ & $72 \mathrm{Ab}$ \\
\hline $\mathrm{S} / \mathrm{C}$ & \multicolumn{3}{|c|}{$3,50 \mathrm{~A}$} & \multicolumn{2}{|c|}{$2,67 \mathrm{a}$} & - & - \\
\hline $\mathrm{C} / \mathrm{C}$ & \multicolumn{3}{|c|}{$3,50 \mathrm{~A}$} & \multicolumn{2}{|c|}{$3,00 \mathrm{~A}$} & - & - \\
\hline C.V. & \multicolumn{3}{|c|}{9,52} & \multicolumn{2}{|c|}{7,65} & \multicolumn{2}{|c|}{8,46} \\
\hline
\end{tabular}

* Médias seguidas da mesma letra (maiúscula para tratamentos e minúscula para lotes), não diferem entre si pelo teste de Tukey a $5 \%$ de probabilidade.

Fonte: Elaboração dos autores.

Também na Tabela 2, durante o desenvolvimento da cultura, foi verificado que o condicionamento osmótico aumentou o diâmetro do caule das plantas, independente do lote utilizado na semeadura. Além disto, este promoveu o maior índice de área foliar das plantas do lote 2 a partir de 60 DAS e, das do lote 3, a partir de 75 DAS (Tabela 3), bem como a maior massa de matéria seca de parte aérea das plantas provenientes dos lotes 2 e 3, a partir de 60 DAS. Em sementes de canola, Basra et al. (2003) verificaram que plantas, oriundas de sementes condicionadas com PEG 10000, apresentaram maior índice de área foliar e acúmulo de massa de matéria seca quando comparado com plantas oriundas de sementes que não foram submetidas ao condicionamento. Plantas que apresentaram maior índice de área foliar conseguem interceptar maior quantidade de radiação solar e converter esta em fotoassimilados, acumulando maior quantidade de massa seca (PEIXOTO; CRUZ; PEIXOTO, 2011).
Na Tabela 4 foi observado aumento linear, com valores máximos aos 97 DAS para massa de matéria seca de parte aérea para todos lotes e tratamentos. Este valor principalmente do lote 2, após as sementes terem sido condicionadas foi superior aos observados por Spettar e Trecenti (2011), que encontraram $6310 \mathrm{~kg} \mathrm{ha}^{-1}$ para o acúmulo de massa de matéria seca, com a cultivar Catissol no município de Planaltina (DF). Também a partir de 60 DAS ocorreu decréscimo nos valores de índice de área foliar para todos os lotes e tratamentos (Tabela 4). Esta redução do índice de área foliar está relacionada às perdas de folhas, oriunda da senescência natural da espécie e à maturação de sementes. Para Schneiter e Miller (1981), a partir deste período (60 DAS) inicia-se a fase de acúmulo de reservas nas sementes de girassol, para que a planta inicie o investimento nas partes reprodutivas em detrimento das partes vegetativas. 
Tabela 2. Dados médios de altura de planta, de número folhas, de diâmetro do caule ( $\mathrm{mm})$, de diâmetro do capítulo $(\mathrm{cm})$, de massa de 1000 sementes $(\mathrm{g})$, de produção de sementes $\left(\mathrm{g} \cdot\right.$ planta $\left.^{-1}\right)$, de produtividade de sementes $\left(\mathrm{kg} \cdot \mathrm{ha}^{-1}\right)$, de índice de colheita, e de número de sementes bem formadas por capitulo, obtidos de plantas provenientes de três lotes (L1, L2 e L3) de sementes de girassol, submetidas (C/C) ou não (S/C) ao condicionamento osmótico.

\begin{tabular}{|c|c|c|c|c|c|c|c|c|}
\hline \multicolumn{2}{|l|}{ Variáveis } & Lote 1 & Lote 2 & Lote 3 & $\mathrm{~S} / \mathrm{C}$ & $\mathrm{C} / \mathrm{C}$ & C.V. ${ }^{1}$ & C.V. ${ }^{2}$ \\
\hline Altura & & $77,70 a^{*}$ & $85,86 a$ & $80,24 a$ & $78,91 \mathrm{~A}$ & $83,63 \mathrm{~A}$ & 21,15 & 16,43 \\
\hline Número de folhas & & $12 \mathrm{a}$ & $14 \mathrm{a}$ & $13 a$ & $13 \mathrm{~A}$ & $13 \mathrm{~A}$ & 25,73 & 13,90 \\
\hline Diâmetro do caule & & $10,72 \mathrm{a}$ & $12,62 \mathrm{a}$ & $11,14 a$ & $10,96 \mathrm{~B}$ & $12,04 \mathrm{~A}$ & 20,42 & 11,96 \\
\hline $\begin{array}{l}\text { Diâmetro do } \\
\text { capitulo }\end{array}$ & & $12,26 \mathrm{a}$ & $13,06 a$ & $12,67 \mathrm{a}$ & $12,57 \mathrm{~A}$ & $13,81 \mathrm{~A}$ & 20,72 & 15,56 \\
\hline Massa de 1000 & & $57,88 \mathrm{a}$ & $57,78 \mathrm{a}$ & $58,60 \mathrm{a}$ & $57,69 \mathrm{~A}$ & $58,47 \mathrm{~A}$ & 3,71 & 2,97 \\
\hline $\begin{array}{l}\text { Produção de } \\
\text { sementes }\end{array}$ & & $42,19 b$ & $52,45 \mathrm{a}$ & $40,97 b$ & $45,00 \mathrm{~A}$ & $45,66 \mathrm{~A}$ & 8,83 & 8,38 \\
\hline $\begin{array}{l}\text { Produtividade de } \\
\text { sementes }\end{array}$ & & $1662,34 \mathrm{a}$ & $1949,08 \mathrm{a}$ & $1657,56 a$ & $1668,63 \mathrm{~A}$ & $1797,35 \mathrm{~A}$ & 11,49 & 11,32 \\
\hline Índice de colheita & & $0,43 \mathrm{a}$ & $0,40 \mathrm{a}$ & $0,41 \mathrm{a}$ & $0,41 \mathrm{~A}$ & $0,38 \mathrm{~A}$ & 22,64 & 17,01 \\
\hline \multirow{2}{*}{$\begin{array}{l}\text { Número de } \\
\text { sementes bem } \\
\text { formadas }\end{array}$} & $\mathrm{S} / \mathrm{C}$ & 749Ab & 893Aa & $666 \mathrm{Bb}$ & - & - & 10,14 & 7,76 \\
\hline & $\mathrm{C} / \mathrm{C}$ & $707 \mathrm{Ab}$ & 930Aa & $815 \mathrm{Aab}$ & - & - & & \\
\hline
\end{tabular}

* Médias seguidas da mesma letra (maiúscula para tratamentos e minúscula para lotes), não diferem entre si pelo teste de Tukey a $5 \%$ de probabilidade. ${ }^{1}$ coeficiente de variação da parcela (lotes) e ${ }^{2}$ coeficiente de variação da subparcela (tratamento de condicionamento).

Fonte: Elaboração dos autores.

Tabela 3. Dados médios de massa de matéria seca da parte aérea total $\left(\mathrm{g} \cdot \mathrm{m}^{-2}\right)$ e de índice de área foliar $\left(\mathrm{m}^{2} \mathrm{~m}^{-2}\right)$, obtidos de plantas provenientes de três lotes (L1, L2 e L3) de sementes de girassol, submetidas (C/C) ou não (S/C) ao condicionamento osmótico. Avaliação aos 15, 30, 45, 60, 75, 90 e 97 DAS.

\begin{tabular}{cccc}
\hline \multicolumn{2}{c}{ Tratamentos } & Índice de área foliar & $\begin{array}{c}\text { Massa de matéria seca da parte aérea } \\
\text { total }\end{array}$ \\
\hline \multirow{6}{*}{$15 \mathrm{DAS}$} & $\mathrm{L} 1$ & $0,024 \mathrm{a}$ & $1,16 \mathrm{a}^{*}$ \\
& $\mathrm{~L} 2$ & $0,025 \mathrm{a}$ & $1,19 \mathrm{a}$ \\
& $\mathrm{L} 3$ & $0,020 \mathrm{a}$ & $0,99 \mathrm{a}$ \\
& $\mathrm{S} / \mathrm{C}$ & $0,022 \mathrm{~A}$ & $1,01 \mathrm{~A}$ \\
& $\mathrm{C} / \mathrm{C}$ & $0,024 \mathrm{~A}$ & $1,21 \mathrm{~A}$ \\
& $\mathrm{~L} 1$ & $0,279 \mathrm{c}$ & $15,02 \mathrm{a}$ \\
& $\mathrm{L} 2$ & $0,503 \mathrm{a}$ & $26,18 \mathrm{a}$ \\
& $\mathrm{L} 3$ & $0,405 \mathrm{~b}$ & $24,51 \mathrm{a}$ \\
& $\mathrm{S} / \mathrm{C}$ & $0,399 \mathrm{~A}$ & $21,57 \mathrm{~A}$ \\
& $\mathrm{C} / \mathrm{C}$ & $0,393 \mathrm{~A}$ & $22,23 \mathrm{~A}$ \\
& $\mathrm{~L} 1$ & $0,820 \mathrm{~b}$ & $69,87 \mathrm{a}$ \\
& $\mathrm{L} 2$ & $1,170 \mathrm{a}$ & $92,48 \mathrm{a}$ \\
& $\mathrm{L} 3$ & $0,859 \mathrm{~b}$ & $59,82 \mathrm{a}$ \\
& $\mathrm{S} / \mathrm{C}$ & $0,860 \mathrm{~B}$ & $65,86 \mathrm{~A}$ \\
& $\mathrm{C} / \mathrm{C}$ & $1,039 \mathrm{~A}$ & $79,00 \mathrm{~A}$
\end{tabular}

continua 
continuação

\begin{tabular}{|c|c|c|c|c|}
\hline \multirow[t]{6}{*}{$60 \mathrm{DAS}$} & L1 & $\mathrm{S} / \mathrm{C}$ & $0,767 \mathrm{Bb}$ & $159,38 \mathrm{Bb}$ \\
\hline & & $\mathrm{C} / \mathrm{C}$ & $1,253 \mathrm{Ab}$ & $248,70 \mathrm{Ab}$ \\
\hline & $\mathrm{L} 2$ & $\mathrm{~S} / \mathrm{C}$ & $1,365 \mathrm{Ba}$ & $258,16 \mathrm{Ba}$ \\
\hline & & $\mathrm{C} / \mathrm{C}$ & $1,692 \mathrm{Aa}$ & $312,18 \mathrm{Aa}$ \\
\hline & L3 & $\mathrm{S} / \mathrm{C}$ & $0,990 \mathrm{Ab}$ & $192,74 \mathrm{Bb}$ \\
\hline & & $\mathrm{C} / \mathrm{C}$ & $1,142 \mathrm{Ac}$ & $234,49 \mathrm{Ab}$ \\
\hline \multirow[t]{6}{*}{75 DAS } & L1 & $\mathrm{S} / \mathrm{C}$ & $0,640 \mathrm{Ab}$ & $316,33 \mathrm{Bb}$ \\
\hline & & $\mathrm{C} / \mathrm{C}$ & $0,727 \mathrm{Ac}$ & $395,67 \mathrm{Ab}$ \\
\hline & $\mathrm{L} 2$ & $\mathrm{~S} / \mathrm{C}$ & 0,720Bab & $407,12 \mathrm{Ba}$ \\
\hline & & $\mathrm{C} / \mathrm{C}$ & $0,926 \mathrm{Aa}$ & $483,34 \mathrm{Aa}$ \\
\hline & L3 & $\mathrm{S} / \mathrm{C}$ & $0,744 \mathrm{Ba}$ & $314,00 \mathrm{Bb}$ \\
\hline & & $\mathrm{C} / \mathrm{C}$ & $0,825 \mathrm{Ab}$ & $362,28 \mathrm{Ab}$ \\
\hline \multirow[t]{6}{*}{$90 \mathrm{DAS}$} & L1 & $\mathrm{S} / \mathrm{C}$ & $0,601 \mathrm{Aa}$ & $434,89 \mathrm{Ab}$ \\
\hline & & $\mathrm{C} / \mathrm{C}$ & $0,612 \mathrm{Ab}$ & $461,08 \mathrm{Ac}$ \\
\hline & $\mathrm{L} 2$ & $\mathrm{~S} / \mathrm{C}$ & $0,537 \mathrm{Bab}$ & $605,16 \mathrm{Ba}$ \\
\hline & & $\mathrm{C} / \mathrm{C}$ & $0,705 \mathrm{Aa}$ & $715,40 \mathrm{Aa}$ \\
\hline & L3 & $\mathrm{S} / \mathrm{C}$ & $0,465 \mathrm{Bb}$ & $448,02 \mathrm{Bb}$ \\
\hline & & $\mathrm{C} / \mathrm{C}$ & $0,672 \mathrm{Aab}$ & $623,78 \mathrm{Ab}$ \\
\hline \multirow[t]{6}{*}{97 DAS } & $\mathrm{L} 1$ & $\mathrm{~S} / \mathrm{C}$ & - & $497,58 \mathrm{Ab}$ \\
\hline & & $\mathrm{C} / \mathrm{C}$ & - & $512,84 \mathrm{Ac}$ \\
\hline & $\mathrm{L} 2$ & $\mathrm{~S} / \mathrm{C}$ & - & $655,26 \mathrm{Ba}$ \\
\hline & & $\mathrm{C} / \mathrm{C}$ & - & $726,63 \mathrm{Aa}$ \\
\hline & L3 & $\mathrm{S} / \mathrm{C}$ & - & $482,46 \mathrm{Bb}$ \\
\hline & & $\mathrm{C} / \mathrm{C}$ & - & $635,04 \mathrm{Ab}$ \\
\hline C.V.(\%) parcela & & & 12,73 & 10,52 \\
\hline C.V.(\%)subparcela & & & 20,12 & 11,88 \\
\hline $\begin{array}{l}\text { C.V.(\%) } \\
\text { subsubparcela }\end{array}$ & & & 12,41 & 14,83 \\
\hline
\end{tabular}

* Médias seguidas da mesma letra (maiúscula para tratamentos e minúscula para lotes), não diferem entre si pelo teste de Tukey a $5 \%$ de probabilidade.

Fonte: Elaboração dos autores. 
Tabela 4. Equações de regressão estimadas ${ }^{1 \mathrm{e} 2}$, do número de folhas por planta, da altura das plantas $(\mathrm{cm})$, do diâmetro do caule $(\mathrm{mm})$, do diâmetro do capítulo $(\mathrm{cm})$, massa de matéria seca da parte aérea total $\left(\mathrm{g} \cdot \mathrm{m}^{-2}\right)$ e de índice de área foliar $\left(\mathrm{m}^{2} \cdot \mathrm{m}^{-2}\right)$, obtidos de plantas provenientes de três lotes de sementes (L1, L2 e L3) de girassol, submetidos (C/C) ou não (S/C) ao condicionamento osmótico, por época de avaliação.

\begin{tabular}{|c|c|c|c|c|}
\hline \multirow{2}{*}{ Tratamentos } & \multicolumn{4}{|c|}{ Parâmetros } \\
\hline & A & $\mathrm{B}$ & $\mathrm{C}$ & $\mathrm{R}^{2}$ \\
\hline & \multicolumn{4}{|c|}{ Número de folhas } \\
\hline & $1,214^{*}$ & $0,716^{* *}$ & $-0,006 * *$ & 0,88 \\
\hline & \multicolumn{4}{|c|}{ Altura das plantas $(\mathrm{cm})$} \\
\hline & $-5,054 * *$ & $1,467 * *$ & - & 0,89 \\
\hline & \multicolumn{4}{|c|}{ Diâmetro do caule (mm) } \\
\hline & $2,96 * *$ & $0,144 * *$ & - & 0,89 \\
\hline & \multicolumn{4}{|c|}{ Diâmetro do capitulo $(\mathrm{cm})$} \\
\hline & $-1,173^{\mathrm{ns}}$ & $0,179 * *$ & - & 0,95 \\
\hline & \multicolumn{4}{|c|}{ Massa de matéria seca da parte aérea total $\left(\mathrm{g} \mathrm{m}^{-2}\right)$} \\
\hline $\mathrm{L} 1-\mathrm{S} / \mathrm{C}$ & $-170,520 * *$ & $6,491 * *$ & - & 0,94 \\
\hline $\mathrm{L} 1-\mathrm{C} / \mathrm{C}$ & $-163,708 * *$ & $6,927 * *$ & - & 0,95 \\
\hline $\mathrm{L} 2-\mathrm{S} / \mathrm{C}$ & $-216,169 * *$ & $8,630 * *$ & - & 0,95 \\
\hline $\mathrm{L} 2-\mathrm{C} / \mathrm{C}$ & $-247,188 * *$ & $9,929 * *$ & - & 0,95 \\
\hline $\mathrm{L} 3-\mathrm{S} / \mathrm{C}$ & $-161,865 * *$ & $6,425^{* *}$ & - & 0,94 \\
\hline \multirow[t]{2}{*}{$\mathrm{L} 3-\mathrm{C} / \mathrm{C}$} & $-223,259 * *$ & $8,526^{* *}$ & - & 0,92 \\
\hline & \multicolumn{4}{|c|}{ Índice de área foliar $\left(\mathrm{m}^{2} \mathrm{~m}^{-2}\right)$} \\
\hline $\mathrm{L} 1-\mathrm{S} / \mathrm{C}$ & $-0,518 * *$ & $0,037 * *$ & $-0,0003 * *$ & 0,92 \\
\hline $\mathrm{L} 1-\mathrm{C} / \mathrm{C}$ & $-0,914 * *$ & $0,064 * *$ & $-0,0005 * *$ & 0,84 \\
\hline $\mathrm{L} 2-\mathrm{S} / \mathrm{C}$ & $-1,016^{* *}$ & $0,076^{* *}$ & $-0,0006^{* *}$ & 0,88 \\
\hline $\mathrm{L} 2-\mathrm{C} / \mathrm{C}$ & $-1,249 * *$ & $0,088 * *$ & $-0,0007 * *$ & 0,89 \\
\hline $\mathrm{L} 3-\mathrm{S} / \mathrm{C}$ & $-0,741 * *$ & $0,054 * *$ & $-0,0004 * *$ & 0,96 \\
\hline $\mathrm{L} 3-\mathrm{C} / \mathrm{C}$ & $-0,824 * *$ & $0,060 * *$ & $-0,0004 * *$ & 0,93 \\
\hline
\end{tabular}

${ }^{1} \mathrm{y}=\mathrm{A}+\mathrm{Bx}(\mathrm{DAS}) \mathrm{e}^{2} \mathrm{y}=\mathrm{A}+\mathrm{Bx}(\mathrm{DAS})+\mathrm{Cx}(\mathrm{DAS})^{2}$

${ }^{n s}$ não significativo, *significativo a $5 \%, * *$ significativo a $1 \%$ probabilidade pelo teste $\mathrm{t}$.

Fonte: Elaboração dos autores.

\section{Produção de sementes}

Houve efeito significativo da interação entre lotes e tratamentos para número de sementes bem formadas por capítulo (Tabela 2) e para teor de óleo (Tabela 5), bem como efeito individual de lotes para produção de sementes (g planta ${ }^{-1}$ ) (Tabela 2). Assim, comparando-se os tratamentos, para o lote 3, o condicionamento osmótico aumentou o número de sementes bem formadas por capítulo por planta (Tabela 2) e o teor de óleo das sementes (Tabela 5) e, para o lote 2, apenas o teor de óleo (Tabela 5). Estes resultados são semelhantes aos observados em relação ao efeito favorável do condicionamento osmótico no acúmulo de massa de matéria seca e no índice de área foliar, para estes lotes 2 e 3 (Tabela 3), indicando que plantas mais vigorosas, ou seja, com maior acúmulo de massa de matéria seca, apresentam maior capacidade de enchimento dos capítulos, característica favorável a planta de girassol, já que a parte econômica desta são as sementes. Hussain et al. (2006), também observaram que o condicionamento osmótico favoreceu o número de sementes de girassol por capítulo, já para o teor de óleo esses autores verificaram menor teor de óleo em sementes condicionadas, indicando que isto aconteceu pois foi observado elevada concentração de proteína nas sementes de girassol. Além disto, comparandose os lotes empregados na semeadura, quando foram ou não condicionados, o lote 2 apresentou maior número de sementes bem formadas, embora 
este valor não tenha diferido do apresentado pelo lote 3 quando condicionado. Quanto a produção de sementes por planta, esta foi maior quando foram usadas sementes do lote 2, independente do tratamento. Este resultado pode estar relacionado a menor população de plantas, já que estas plantas provenientes do lote 2 estavam em menor número na área, independente do tratamento por apresentarem menor vigor (Tabela 1). De acordo Marcos Filho (2005), quando é obtida baixa população de plantas por unidade de área em decorrência da utilização de sementes de menor vigor, a produção pode ser prejudicada, porém as plantas possuem capacidade de adaptação ao espaço mais amplo para o seu desenvolvimento, exibindo com isso, a elevação da produção individual $\left(\mathrm{g}_{\text {planta }}{ }^{-1}\right)$. Também na Tabela 2 , não houve efeito significativo da interação entre lotes e tratamentos, bem como de efeitos individuais de tratamentos e lotes na produtividade de sementes (Tabela 2). Assim, a produtividade de sementes não variou entre os lotes, mesmo quando as plantas do lote 2 produziram maior quantidade de sementes $\left(\mathrm{g} \mathrm{planta}^{-1}\right)$ (Tabela 2). Além disso, estes valores de rendimento de sementes de girassol estão acima da média Brasileira que é de $1.445 \mathrm{~kg} \mathrm{ha}^{-1}$, para a safra de 2012/2013 (CONAB, 2013), favorecidos provavelmente pela ocorrência de precipitação pluvial superior a $8 \mathrm{~mm} \mathrm{dia}^{-1}$ no período da floração e acúmulo de reserva das sementes, que ocorre de acordo com Schneiter e Miller (1981) dos 45 aos 60 DAS. No entanto, em canola e soja, respectivamente, Basra et al. (2003) e Arif et al. (2008) verificaram que o condicionamento osmótico favoreceu a produção de sementes por hectare.

Tabela 5. Dados médios de sementes retidas na peneira de crivo circular de diâmetro de 5,56 mm (\%), de grau de umidade (\%), de germinação (\%), de porcentagem de plântulas normais na primeira contagem do teste de germinação, de envelhecimento acelerado com solução saturada (\%), de condutividade elétrica $(\mathrm{mS} / \mathrm{cm} / \mathrm{g})$, de emergência de plântulas em areia e campo (\%), de índice de velocidade de emergência de plântulas em areia e campo (IVE) e de teor de óleo, obtidos de sementes de girassol colhidas de plantas provenientes de três lotes de sementes (L1, L2 e L3), submetidas $(\mathrm{C} / \mathrm{C})$ ou não $(\mathrm{S} / \mathrm{C})$ ao condicionamento osmótico. Avaliação após três meses da colheita.

\begin{tabular}{|c|c|c|c|c|c|c|c|}
\hline \multicolumn{2}{|l|}{ Variáveis } & Lote 1 & Lote 2 & Lote 3 & $\mathrm{~S} / \mathrm{C}$ & $\mathrm{C} / \mathrm{C}$ & C.V. $(\%)$ \\
\hline \multicolumn{2}{|l|}{ Grau de umidade } & 6,69 & 6,34 & 6,49 & 6,66 & 6,36 & - \\
\hline \multicolumn{2}{|l|}{ Sementes retidas } & $93,66 a^{*}$ & $95,17 \mathrm{a}$ & $97,37 \mathrm{a}$ & $94,96 \mathrm{~A}$ & $95,83 \mathrm{~A}$ & 2,40 \\
\hline \multicolumn{2}{|l|}{ Germinação } & $82 b$ & $77 b$ & $90 \mathrm{a}$ & $83 \mathrm{~A}$ & $83 \mathrm{~A}$ & 5,87 \\
\hline \multicolumn{2}{|l|}{ Primeira contagem } & $69 \mathrm{~b}$ & $64 b$ & $80 \mathrm{a}$ & $70 \mathrm{~A}$ & $71 \mathrm{~A}$ & 10,30 \\
\hline \multicolumn{2}{|l|}{ Emergência de plântulas em areia } & $96 a$ & $97 \mathrm{a}$ & $96 a$ & $96 \mathrm{~A}$ & $98 \mathrm{~A}$ & 2,36 \\
\hline \multicolumn{2}{|l|}{ IVE em areia } & $15,62 \mathrm{a}$ & $15,50 \mathrm{a}$ & $15,25 \mathrm{a}$ & $14,50 \mathrm{~B}$ & $16,51 \mathrm{~A}$ & 5,76 \\
\hline \multicolumn{2}{|l|}{ Envelhecimento acelerado } & $65 b$ & $65 b$ & $77 \mathrm{a}$ & $71 \mathrm{~A}$ & $68 \mathrm{~A}$ & 13,04 \\
\hline \multicolumn{2}{|l|}{ Condutividade elétrica } & $46,93 b$ & $54,66 \mathrm{a}$ & $40,04 \mathrm{c}$ & $46,00 \mathrm{~A}$ & $48,42 \mathrm{~A}$ & 8,63 \\
\hline \multicolumn{2}{|l|}{ Emergência de plântulas em campo } & $93 \mathrm{a}$ & $95 \mathrm{a}$ & $94 \mathrm{a}$ & $91 \mathrm{~B}$ & $97 \mathrm{~A}$ & 6,18 \\
\hline \multicolumn{2}{|l|}{ IVE em campo } & $14,65 \mathrm{a}$ & $14,20 \mathrm{a}$ & $14,21 \mathrm{a}$ & $12,99 \mathrm{~B}$ & $15,70 \mathrm{~A}$ & 7,21 \\
\hline \multirow{2}{*}{ Teor de óleo } & $\mathrm{S} / \mathrm{C}$ & $42,51 \mathrm{Aa}$ & $38,00 \mathrm{Ba}$ & $38,85 \mathrm{Ba}$ & - & - & \multirow{2}{*}{5,98} \\
\hline & $\mathrm{C} / \mathrm{C}$ & $41,00 \mathrm{Aa}$ & $43,29 \mathrm{Aa}$ & $44,75 \mathrm{Aa}$ & - & - & \\
\hline
\end{tabular}

* Médias seguidas da mesma letra (maiúscula para tratamentos e minúscula para lotes), não diferem entre si pelo teste de Tukey a $5 \%$ de probabilidade.

Fonte: Elaboração dos autores. 
Ao avaliar o índice de colheita, não houve efeito significativo da interação entre lotes e tratamentos, bem como houve efeito individual de lotes e tratamentos para esta variável (Tabela 2). No entanto, estes valores de índice de colheita estão acima dos valores encontrados por Hussain et al. (2006), que foi de 0,32. Monteiro (2001) indica o girassol como cultura com baixa eficiência na partição dos fotoassimilados. As espécies oleaginosas como o girassol, as quais são ricas em lipídios, necessitam de maior quantidade de glicose e minerais para a produção de 1 grama de biomassa de semente, pois a via metabólica dos lipídios consome maior quantidade de esqueletos de carbono do que a via metabólica do amido, com base em Munier-Jolain e Salon (2005).

\section{Qualidade fisiológica das sementes produzidas}

Houve apenas efeito significativo de tratamentos para o vigor das sementes avaliado pelos testes conduzidos em areia e solo (Tabela 5) e, efeito significativo de lotes para germinação e vigor (primeira contagem, condutividade elétrica e envelhecimento acelerado). Assim o condicionamento osmótico favoreceu o vigor das sementes produzidas, quando avaliado pelos testes de IVE em areia e em campo e emergência de plântulas em campo (Tabela 5), independente do lote de sementes utilizado na semeadura. Além disto, independente do tratamento, as sementes produzidas de plantas provenientes do lote 3 (Tabela 5) apresentaram maior germinação e vigor, quando avaliado pelos testes de primeira contagem, envelhecimento acelerado e condutividade elétrica (Tabela 5). Estes resultados são semelhantes aos observados em relação ao efeito favorável do condicionamento osmótico para o lote 3, no acúmulo de massa de matéria seca e no índice de área foliar (Tabela 3). Para Carvalho e Nakagawa (2000), sementes com maior acúmulo de massa seca apresentam maior vigor.

\section{Avaliação de macronutrientes nas sementes}

Houve efeito significativo da interação entre lotes e tratamentos somente para acumulo de potássio, efeito individual de tratamentos para acúmulo de cálcio e de nitrogênio e efeito individual de lotes para acúmulo de nitrogênio e fósforo (Tabela 6). Assim, para o lote 1, o condicionamento favoreceu o acúmulo de potássio e, na comparação entre lotes, quando as sementes foram ou não condicionadas, as do lote 2 apresentaram maior acúmulo deste nutriente. O maior acúmulo de potássio nas sementes está relacionado com a elevada mobilidade deste macronutriente das partes mais velhas da planta para as partes mais novas, durante o processo de senescência natural (LEITE; BRIGHENTI; CASTRO, 2005). Além disto, o lote 2 apresentou maior acúmulo de nitrogênio e fósforo, independente do tratamento (Tabela 6). Plantas do lote 2 apresentaram maior índice de área foliar (Tabela 3), com isso conseguiram interceptar maior quantidade de radiação solar e converter esta em fotoassimilados, acumulando maior quantidade de nitrogênio em suas folhas, pois o nitrogênio é constituinte de moléculas de clorofila e ácidos nucléicos (BOTELHO; PEREZ, 2001). $\mathrm{E}$, independente do lote de sementes utilizado na semeadura, o condicionamento osmótico favoreceu o acúmulo de nitrogênio das sementes e reduziu o de cálcio (Tabela 6). Este resultado de maior conteúdo de nitrogênio das sementes submetidas ao condicionamento pode ter favorecido o vigor das sementes produzidas avaliado principalmente pela velocidade de emergência (Tabela 5). Para Botelho e Perez (2001), o nitrogênio, dentre outras funções, é constituinte das moléculas de poliamina, as quais possuem função na síntese e atividade de macromoléculas, na permeabilidade das membranas e processos parciais de mitose e meiose. Em relação aos dados de redução de cálcio, Raven et al. (1990) relatam que na adubação de semeadura como fonte de nitrogênio quando usa-se nitrato, as plantas absorvem mais cátions e quando se usa amônia, que foi utilizado neste cultivo, as plantas absorvem mais 
anions e consequentemente diminuem a absorção de cátions. Comparando os valores com os da literatura, estes estão de acordo com os encontrados nas sementes de girassol por Braz e Rossetto (2010) observaram 88, 30, 30 e $16 \mathrm{~kg} \mathrm{ha}^{-1}$ de N, P, K e Ca respectivamente em sementes de girassol da cultivar Embrapa 122 V2000.
Desta forma pode-se considerar que, o condicionamento osmótico promove mudanças metabólicas no crescimento e desenvolvimento da planta, sendo estas específicas de acordo com o nível de vigor das sementes utilizadas na semeadura.

Tabela 6. Dados médios de acúmulo de nitrogênio, fósforo, potássio, cálcio e magnésio $\left(\mathrm{kg} \mathrm{ha}^{-1}\right)$ nas sementes, obtidos de plantas provenientes de três lotes (L1, L2 e L3) de sementes de girassol, submetidas (C/C) ou não (S/C) ao condicionamento osmótico.

\begin{tabular}{|c|c|c|c|c|c|c|c|c|}
\hline Variáveic & & Lote 1 & Lote 2 & Lote 3 & $\mathrm{~S} / \mathrm{C}$ & $\mathrm{C} / \mathrm{C}$ & C.V. ${ }^{1}$ & C.V. ${ }^{2}$ \\
\hline Nitrogênio & & $110,40 b^{*}$ & $155,45 \mathrm{a}$ & $108,18 b$ & $116,80 \mathrm{~B}$ & $132,55 \mathrm{~A}$ & 12,56 & 10,24 \\
\hline Fósforo & & $23,24 b$ & $28,73 a$ & $26,18 b$ & $27,72 \mathrm{~A}$ & $24,39 \mathrm{~A}$ & 10,92 & 13,99 \\
\hline Cálcio & & $11,97 \mathrm{a}$ & $12,09 \mathrm{a}$ & $12,15 \mathrm{a}$ & $12,47 \mathrm{~A}$ & $11,68 \mathrm{~B}$ & 7,37 & 6,74 \\
\hline Magnésio & & $5,17 \mathrm{a}$ & $4,37 \mathrm{a}$ & $5,14 \mathrm{a}$ & $4,97 \mathrm{~A}$ & $4,82 \mathrm{~A}$ & 21,17 & 21,80 \\
\hline Potássio & $\mathrm{S} / \mathrm{C}$ & $22,81 \mathrm{Ab}$ & $27,31 \mathrm{Aa}$ & $22,25 \mathrm{Ab}$ & - & - & 6,60 & 7,38 \\
\hline
\end{tabular}

* Médias seguidas da mesma letra (maiúscula para tratamentos e minúscula para lotes), não diferem entre si pelo teste de Tukey a $5 \%$ de probabilidade. ${ }^{1}$ coeficiente de variação da parcela (lotes) e ${ }^{2}$ coeficiente de variação da subparcela (tratamento de condicionamento).

Fonte: Elaboração dos autores.

\section{Conclusão}

O condicionamento osmótico favorece a sobrevivência das plantas, o acúmulo de massa de matéria seca da parte aérea de plantas a partir de 60 dias após a semeadura e o teor de óleo, em plantas provenientes de lotes de sementes de qualidade inferior.

O condicionamento osmótico não aumenta a produtividade de sementes, mas favorece o vigor das sementes produzidas, independente da qualidade de sementes do lote utilizado na semeadura.

\section{Agradecimentos}

Os autores agradecem a CAPES e ao CNPq pelas bolsas de pesquisa e a FAPERJ pelo auxilio financeiro.

\section{Referências}

ARIF, M.; JAN, M. T.; MARWAT, K. B.; KHAN, M. A. Seed priming improves emergence and yield of soybean. Pakistan Journal of Botany, Karachi, v. 40, n. 3, p. 11691177, 2008.

BARROS, C. S.; ROSSETTO, C. A. V. Condicionamento fisiológico de sementes de girassol. Ciência Rural, Santa Maria, v. 39, n. 6, p. 1667-1675, 2009.

BASRA, M. A. S.; ULLAH, E.; WARRAICH, E. A.; CHEEMA, M. A.; AZFAL, I. Effect of Storage on growth and yield of primed canola (Brassica napus) seeds. International journal of agriculture and biology. Faisalabad, v. 5, n. 2, p. 117-120, 2003.

BOTELHO, B. A.; PEREZ, S. C. J. G. A. Estresse hídrico e reguladores de crescimento na germinação de sementes de Canafistula. Scientia Agrícola, Piracicaba, v. 58, n. 1, p. 43-49, 2001.

BRASIL. Ministério da Agricultura e Reforma Agrária. Regras para análise de sementes. Brasília: SNDA/ DNDV/CLAV, 2009. 398 p. 
BRAZ, M. R. S.; BARROS, C. S.; CASTRO, F. P.; ROSSETTO, C. A. V. Testes de envelhecimento acelerado e deterioração controlada na avaliação do vigor de aquênios de girassol. Ciência Rural, Santa Maria, v. 38, n. 7, p. 1857-1863, 2008.

BRAZ, M. R. S.; ROSSETTO, C. A. V. Crescimento de plantas de girassol em função do vigor de aquênios e da densidade de semeadura. Ciência Rural, Santa Maria, v. 39, n. 7, p. 1762-1771, 2009.

Acúmulo de nutrientes e rendimento de óleo em plantas de girassol influenciados pelo vigor dos aquênios e pela densidade de semeadura. Semina: Ciências Agrárias, Londrina, v. 31, p. 1193-1204, 2010. Suplemento 1.

CARVALHO, N. M.; NAKAGAWA, J. Sementes: ciência, tecnologia e produção. 4. ed. Jaboticabal: Funep, 2000. 588 p.

COMPANHIA NACIONAL DE ABASTECIMENTO CONAB. Acompanhamento de safra brasileira: grãos, sexto levantamento, março 2013. Companhia Nacional de Abastecimento. Brasília: Conab, 2013. 26 p.

COSTA, C. J.; VILLELA, F. A. Condicionamento osmótico de sementes de beterraba. Revista Brasileira de Sementes, Brasília, v. 28, n. 1, p. 21-29, 2006.

HEYDECKER, W.; HIGGINS, J.; TURNER, Y. J. Invigoration of seeds? Seed Science and Technology, Zurich, v. 5, n. 2, p. 881-888, 1975.

HUSSAIN, M.; FAROOQ, M.; BASRA, S. M. A.; AHMAD, N. Influence of seed priming techniques on the seedling establishment, yield and quality of hibrid sunflower. International Journal of Agriculture and Biology, Faisalabad, v. 8, n. 1, p. 14-18, 2006.

KIMBINZA, S.; BAZIN, J.; BAILLY, C.; FARRANT, J. M.; CORBINEAU, F.; BOUTEAU, H. M. Catalase is a key enzyme in seed recovery from ageing during priming. Plant Science, Limerick, v. 181, n. 3, p. 309-315, 2011.

KVET, J.; ONDOK, J. P.; NECAS, J.; JARVIS, P. G. Methods of growth analysis. In: SESTÁK, Z.; CATSKY, J.; JARVIS, P. G. (Ed.). Plant photosynthetic productionmanual of methods. The Hague: W Junk N.V. Publishers, 1971. p. 343-391.

LEITE, R. M. V. B. C.; BRIGHENTI, A. M.; CASTRO, C. (Ed.). Girassol no Brasil. Londrina: Embrapa Soja, 2005. 612 p.

LIMA, L. B.; MARCOS FILHO, J. Procedimentos para condução de testes de vigor baseados na tolerância ao estresse térmico em sementes de pepino. Revista Brasileira de Sementes, Brasília, v. 33, n. 1, p. 45-53, 2011.
MARCOS FILHO, J. Condicionamento fisiológico de sementes. In: (Ed.). Fisiologia de sementes de plantas cultivadas. Piracicaba: Fealq, 2005. cap. XI, p. 383-427.

MONTEIRO, C. de A. Análise de crescimento e produtividade agrícola de girassol conduzido na safrinha em cinco densidades de plantas. 2001. Dissertação (Mestrado em Fitotecnia) - Escola Superior de Agricultura Luiz de Queiroz, Piracicaba.

MUNIER-JOLAIN, N.; SALON, C. Are the carbon costs of seed production related to the quantitative and qualitative performance? An appraisal for legumes and other crops. Plant, Cell and Environment, Oxford, v. 28, n. 11, p. 1388-1395, 2005.

MWALE, S. S.; HAMUSIMBI, C.; MWANSA, K. Germination, emergence and growth of sunflower (Helianthus annuus L.) in response to osmotic seed priming. Seed Science and Technology, Zurich, v. 31, n. 1, p. 199-206, 2003.

NAKAGAWA, J. Testes de vigor baseados no desempenho das plântulas. In: KRZYZANOWSKI, F. C.; VIEIRA, R. D.; FRANÇA NETO, J. B. (Ed.). Vigor de sementes: conceitos e testes. Londrina: ABRATES, 1999. cap. II, p. 1-24.

PEIXOTO, C. P.; CRUZ, T. V.; PEIXOTO, M. de F. da S. P. Análise quantitativa do crescimento de plantas: conceitos e prática. Enciclopédia Biosfera, Centro Cientifico Conhecer, Goiânia, v. 7, n. 13, p. 51-79, 2011.

RAIJ, B. V.; CANTARELLA, H.; QUAGGIO, J. A.; FURLANI, A. M. C. Recomendações de adubação e calagem para o Estado de São Paulo. 2. ed. Campinas: Instituto Agronômico/Fundação IAC, 1997. 198 p.

RAVEN, J. A.; FRANCO, A. A.; JESUS, E. L.; JACOB NETO, J. H+ extrusion and organic-acid synthisis in N2 fixing symbioses involving vascular plants. New Phytologist, New York, v. 114, n. 3, p. 369-389, 1990.

SANCHEZ, J.A.; ORTA, R.; MUNOZ, B. C. Tratamientos pregerminativos de hidratacion-deshidratacion de las semillas y sus efectos en plantas de interes agrícola. Agronomia Costarricense, San José, v. 25, n. 1, p. 67-92, 2001.

SCHNEITER, A. A.; MILLER, J. F. Description of sunflower growth stages. Crop Science, Madison, v. 21, n. 1, p. 901-903, 1981.

SILVA, H. P.; BRANDÃO JUNIOR, D. S.; SAMPAIO, R. A.; DUARTE, R. F.; NEVES, J. M. G.; AQUINO, C. F. Momento ideal para a colheita do girassol em função da coloração do dorso dos capítulos. Agrarian, Dourados, v. 2, n. 4, p. 41-48, 2009. 
SPETTAR, C. R.; TRECENTI, R. Desempenho agronômico de espécies tradicionais e inovadoras da agricultura em semeadura de sucessão e entresafra no cerrado do planalto central brasileiro. Bioscience Journal, Uberlândia, v. 27, n. 1, p. 102-111, 2011.
WAHID, A.; NOREEN, A.; BASRA, S. M. A.; GELANI, S.; FAROOQ, M. Priming-induce metabolic changes in sunflower (Helianthus annuus L) achene improve germination and seedling growth. Botanical Studies, Taiwan, v. 49, n. 2, p. 343-350, 2008. 